\title{
Reforma do Ensino Médio \\ O que querem os golpistas
}

$\mathrm{E}$ $m$ todas as instâncias e instituições brasileiras, o Golpe perpetrado contra o povo, há pouco mais de um ano, já disse a que veio: destruir a democracia do País, através da desconstrução da Constituição de 1988. Todas as iniciativas desse governo ilegítimo afetam diretamente a educação, como ficou claro na primeira hora.

Na entrevista ao Dossiê sobre a Reforma do Ensino Médio, Retratos da Escola ouviu a professora/doutora Lisete Regina Gomes Arelaro'.

Com toda uma vida dedicada à educação pública, Lisete Arelaro, do alto de sua expertise, sabe muito bem o que pretendem os que se apossaram do País. E lança o desafio, que a todos nós diz respeito: "professores, alunos, especialistas, pesquisadores, movimentos sociais, pais e mães" temos que estar "juntos, discutindo e propondo coletiva e permanentemente, para ter condições de enfrentá-los".

RE - A discussão em torno do ensino médio tem mobilizado profissionais da educação ao longo dos últimos anos no Brasil, colocando em cena diferentes atores sociais. Qual sua avaliação a respeito da atual reforma sancionada pela Lei 13.415/2017?

“...esse grupo do governo atual sabe que não conseguiria enfrentar uma discussão minimamente legítima e consistente com as associações científicas, profissionais, de estudantes e movimentos sociais diversos."
Lisete Arelaro - Nem a ditadura civil-militar dos anos de 1960 utilizou-se de Medida Provisória (leia-se Decreto-Lei) para impor uma reforma de ensino, a não ser a imposição de disciplinas como Educação Moral e Cívica e Educação Física. A lei de reforma dos ensinos de $1^{\underline{0}}$ e $2^{\underline{0}}$ graus, a de $n^{\circ} 5692 / 1971$, obedeceu aos trâmites legais, apesar da óbvia limitação de discussões. Mas, agora, por suposto, estamos numa democracia e não se justifica a imposição "goela abaixo" dessa reforma do ensino médio. A razão é que esse grupo do governo atual sabe que não conseguiria enfrentar uma discussão minimamente legítima e consistente com as associações científicas, profissionais, de estudantes e movimentos sociais diversos. Então, apelaram, ao "silêncio" da sociedade. Mas, ela está gritando...

RE - A Lei 13.415/2017 produz mudanças na LDB 9394/96, em três diferentes aspectos: na organização curricular, na carga horária mínima atual e no financiamento. A Portaria 1.145/2016 estabelece as condições para sua implantação pelas redes públicas. Quais os impactos desse processo, uma vez que a implantação decorre da adesão das escolas ao chamado Programa de Fomento à implementação das escolas em tempo integral?

Lisete Arelaro - As condições reais do ensino público no Brasil, pós-EC noำ 95/2016, vão impedir, a curto prazo, a implantação da Lei. O governo atual acredita que se eles 
fizerem um controle "canino" em cima das escolas e das redes de ensino todos vão se enquadrar. Ledo engano. A última ditadura, a dos anos de 1964/1985, não conseguiu impor a profissionalização obrigatória e terminal do ensino de $2^{\circ}$ grau, nome da época para o atual ensino médio. Por quê? Porque o governo militar tinha que investir muito mais recursos financeiros do que se dispôs. E, portanto, poucos anos depois, já em 1975, ela estava sem efeito, na prática. Este é o caminho que, espero, a Lei percorra. Não haverá investimento como se precisa e eles não ficarão no e com o governo tanto tempo quanto desejam. Será a melhor coisa que acontecerá para os jovens e sua formação escolar.

\section{RE - A Lei 13.415/2017 prevê a manutenção da oferta do ensino médio no período} noturno (EJA e cursos regulares), ao mesmo tempo que estabelece a carga horária anual de 1.400 horas, a ser implantada de forma gradual, num prazo máximo de cinco anos (já considerando 2017) para que os sistemas ofereçam pelo menos 1000 horas/ anuais. Considerando o tempo destinado às aulas no ensino noturno, isso será possível? Que tendências podem ser observadas para o cumprimento dessa carga horária no caso no ensino noturno?

Lisete Arelaro - Na verdade, a Lei não detalha nada, até porque o grupo que a propôs não tem e não sabe o que dizer. E também não estão muito preocupados com os estudantes. É evidente que eles e nós sabemos que 800 horas anuais é o máximo que se pode propor para a situação: o aluno trabalhador, estudante do período noturno, com idade dita regular de 15 a 17 anos ou o maior de 21 anos. Mas, deveriam ser dois projetos diferentes, a EJA e os cursos noturnos chamados "regulares". O primeiro exige organização especial e dentro das condições de vida e trabalho dos(as) estudantes um bom número deles com 15 a 19 anos de idade. Os trabalhadores mais velhos têm, em geral, uma jornada de trabalho bastante pesada e já chegam na escola depois de $8 \mathrm{~h}$ a 10 horas de trabalho, daí porque defendem que os projetos de formação possam e devam ser mais flexíveis. Mil horas/ano ou 1.400/ano para período integral não será implantado ou será simulacro na EJA. Ou, se formos cínicos, basta reduzir a hora/aula para 40 minutos e se terá "cumprido a exigência legal"... Mas, a maioria de cursos de EJA e de cursos regulares em períodos noturnos não têm atendido as necessidades dos jovens e dos adultos. É preciso mais respeito, melhores condições de funcionamento e criatividade para eles.

RE - As propagandas governamentais justificam a reforma, aludindo ao protagonismo dos jovens e sua necessidade de escolha. Que concepções se alinham a estes dois termos - protagonismo e liberdade de escolha?

Lisete Arelaro - Eu gostaria muito que nossos jovens fossem protagonistas de suas escolhas curriculares, a partir de uma sólida e diversificada formação curricular. Acho 
ridículo o governo achar as 13 disciplinas atuais um "absurdo", que "confundem" os jovens, e propondo uma opção por percurso formativo aos 14, 15 anos de idade, quando sabemos que, nem quando chegam à universidade, depois de exames seletivos, sabem exatamente se o curso que estão fazendo traduz o que queriam fazer...Basta olhar o número de desistências e/ou mudanças de curso no decorrer do ensino superior. A propaganda confunde formação profissional (o que quero fazer quando me formar...) com opção pelos virtuais, e potencialmente falsos, percursos formativos, procurando destruir a concepção de formação unificada para o ensino médio.

RE - A organização curricular estruturada a partir de itinerários formativos - cinco, incluindo a formação técnica e profissional - romperia com a concepção de "educação básica" que norteia a LDB 9394/96?

Lisete Arelaro - Faço parte do grupo que entende que superar a histórica divisão do antigo colegial em "clássico" versus "científico" havia sido um ganho. E que o ensino médio integrado era a melhor alternativa para um(a) jovem que quisesse fazer um curso técnico profissional. Não vejo problemas, depois da formação básica, como etapa com currículo comum a todos (as) os (as) jovens, haver uma opção de aprofundamento de estudos. Mas, não é isso que eles pretendem. Eles pretendem, sim, reduzir a formação geral da juventude, com redução da diversidade curricular. Não nos iludamos: transformar Arte, Sociologia, Filosofia e Educação Física em "estudos e práticas" é, no máximo, considera-los "temas transversais", ou seja, vai-se trabalhar com eles quando der e convier. A aparente contradição em considerar Arte como "obrigatória" no Art. 2o e como "estudos e práticas" no Art. 3ํㅡㄹ não é mera coincidência, é proposital.

RE - A Lei 13.415/2017 prevê que a carga horária dedicada às disciplinas e conteúdos da BNCC não pode ser superior a $\mathbf{1 8 0 0}$ horas da carga horária total do ensino médio. Isso abre possibilidade para que as redes decidam por dedicar menos carga horária a este "bloco" de formação? Que impactos teremos na formação dos jovens, visto que disciplinas como Artes, Sociologia, Filosofia e Educação Física estão previstas apenas na composição deste "bloco"?

Lisete Arelaro - A resposta é afirmativa. Sim: eles acham que jovens não precisam ter uma formação consistente, curiosa e crítica para o fim que eles propõem como futuro do Brasil. Se tiverem bons resultados nas provas nacionais, que terão como conteúdo obrigatório as propostas constantes da BNCC, já é o suficiente. Até porque gestão democrática não é o forte deles e esse grupo, historicamente, considera que discutir significa terem que abrir mão de suas posições. E isso, eles não querem e não pretendem. Daí a importância de professores, alunos, especialistas, pesquisadores, movimentos sociais, 
pais e mães estarmos juntos, discutindo e propondo coletiva e permanentemente, para ter condições de enfrentá-los.

Retratos - Uma das críticas contundentes à nova Lei é sua abertura para as parcerias "público-privadas" para a execução da atividade-fim, ou seja, a formação. Isso fica bem definido no caso do itinerário "Formação Técnica e Profissional". Qual sua avaliação?

Lisete Arelaro - Há pouco tempo, já tivemos uma experiência ruim com a formação técnica profissional proposta no governo Dilma, com o Pronatec, que transferiu recursos públicos para os privados, especialmente para o Sistema $S$, e cujos resultados foram ridículos. A situação é pior agora, pois é um grupo que defende, de forma coesa, a prática das parcerias público-privadas como a melhor (ou a única) alternativa para melhorar a qualidade da educação pública e, em especial, do ensino médio. Veja-se, dentre outras, a intervenção do Unibanco na questão. Esse grupo do governo nunca deu aula no ensino público ou o fez há mais de 40 anos, não tendo a mínima ideia do que acontece nele. Exemplo disso é que eles continuam insistindo na chamada Pedagogia das Competências, acreditando que a uma somatória de conteúdos corresponde uma, duas ou três "habilidades". E agora, o Mediotec do governo Temer (antecipando a reforma do ensino médio) ou o Programa de Fomento são piores ainda. Parcerias público-privadas para esse governo faz parte do programa internacional de privatização e mercantilização da educação, como aliás consta da Portaria nº 983, de 26/08/2016, buscando tirar todas as dificuldades legais para a entrada de grupos (oligopólios) internacionais, onde se propõe textualmente "trabalhar em colaboração e prover insumos ao Ministério das Relações Exteriores - MRE, para preparação da lista negativa para efeitos de negociações internacionais no comércio de serviços, no âmbito dos setores e subsetores de serviços relacionados à Educação" (item II, do art. $1^{\underline{o}}$ ).

\section{RE - Que impacto você avalia que a nova Lei do Ensino Médio poderá ter na forma- ção dos professores?}

Lisete Arelaro - O grupo que hoje está no MEC já é bastante conhecido, já que atuou nos governos FHC I e II e pretende que as suas ideias - e só as dele - estejam presentes na educação e nas políticas, anulando toda sadia divergência em relação a elas. Bom exemplo disso é a Deliberação do Conselho Estadual de São Paulo, a de n⿳ํㅜㄴ 154, de junho/2017, alterando profundamente as últimas negociações realizadas pelas universidades estaduais paulistas (Deliberação n⿳0 126/2014), quando esse grupo ainda não era governo e tinha que negociar com as associações científicas, profissionais e sindicais. A proposta de redução da carga horária de formação teórica de todos os cursos de licenciatura, mas principalmente em relação aos cursos de Pedagogia, traduz a desconsideração “...é um grupo que defende, de forma coesa, a prática das parcerias públicoprivadas como a melhor (ou a única) alternativa para melhorar a qualidade da educação pública e, em especial, do ensino médio. Vejase, dentre outras, a intervenção do Unibanco na questão."

"Parcerias públicoprivadas para esse governo faz parte do programa internacional de

privatização e mercantilização da educação, (...), buscando tirar todas as dificuldades legais para a entrada de grupos (oligopólios) internacionais..." 
"O grupo que hoje está no MEC já é bastante conhecido, já que atuou nos governos FHC I e II e pretende que as suas ideias - e só as deleestejam presentes na educação e nas políticas, anulando toda sadia divergência em relação a elas."

\section{"A pergunta \\ que eles não} respondem: vai ter

bolsa de estudos elou transporte e alimentação gratuita para todos(as) os(as) estudantes que tiverem que estudar no município vizinho ou em tempo integral?" por uma formação consistente, pois o que eles (as) pretendem é que a proposta da BNCC - a deles! - seja o conteúdo quase exclusivo dos cursos de formação de professores em todas as licenciaturas.

RE - O Programa de Fomento à adesão das escolas ao ensino médio integral prevê a suplementação de recursos financeiros para as escolas que aderirem ao Programa, ao mesmo tempo em que estabelece tanto o quantitativo de escolas/estado e o tempo máximo de ajuda (48 meses). Qual sua avaliação a respeito desta situação, posto que a maioria das escolas está fora do Programa de Fomento?

Lisete Arelaro - É mais uma proposta demagógica, para parecer que eles estão preocupados com o ensino médio público. Não estão. Tenho ouvido secretários (as) de educação municipal e estadual dizendo ser impossível seguir o que eles pretendem. $\mathrm{O}$ dinheiro que será disponibilizado não contempla as necessidades reais de uma escola de ensino médio em período integral, com condições materiais e de infraestrutura minimamente necessárias, currículo mais diversificado, professores melhor remunerados e com jornada de trabalho numa só escola, dentre outros aspectos. Agrava este fato que em muitos municípios do Brasil existe uma só escola de ensino médio e, em alguns, nenhuma escola. A pergunta que eles não respondem: vai ter bolsa de estudos e/ou transporte e alimentação gratuita para todos(as) os(as) estudantes que tiverem que estudar no município vizinho ou em tempo integral?

RE - O Programa de Fomento à implementação do novo ensino médio (integral) já está alicerçado em metas, condicionando a manutenção de recursos financeiros suplementares aos resultados de avaliações que apontem o seu cumprimento. Essa tendência gerencialista, na sua opinião, pode ampliar-se, balizando também outras etapas ou níveis de ensino, como por exemplo, o ensino superior?

Lisete Arelaro - Como mencionei, eles já começaram por São Paulo (lembrando que é o mesmo grupo de Brasília) sua intromissão no ensino superior, alterando (ou acreditando que vão alterar obrigatoriamente, apesar da autonomia pedagógica das universidades) as propostas de formação de professores nos cursos de licenciaturas. Em relação a vincular rendimento/produtividade/resultados com recebimento de recursos financeiros, com as exigências que a pós-graduação, via Currículo Lattes, vem exigindo, já se vem fazendo isso. Eles só acelerarão. É importante lembrar que mesmo no Governo Lula, a exigência de elaboração e cumprimento do PAR/PDE constituía pressuposto para o recebimento de recursos federais. Por outro lado, como 11 estados já possuem legislação que vincula o recebimento de gratificações pelo magistério aos resultados obtidos pelos alunos nas provas nacionais, o cenário já está comprometido com essa concepção. 
RE - Há uma relação orgânica/intima entre a atual reforma do ensino médio com outras reformas, em particular aquela que visa criar novas regulações para formas de emprego e assalariamento?

Lisete Arelaro - Sem dúvida. Lembremo-nos que estávamos em processo final e bastante democrático - de elaboração de lei sobre o ensino médio, que passou a ser devida e exaustivamente discutida com estudantes, associações científicas e de profissionais do magistério junto à Comissão Especial da Câmara Federal que traduzia as expectativas da juventude e de professores para o futuro do Brasil, dentro de uma perspectiva de desenvolvimento nacional. Moderna e consistente era aquela proposta, que começou a partir das discussões para o combate e substituição do PL 6.840/2013. Um (a) trabalhador (a) mal formado pode ser massa de manobra de patrões, empresas e organizações. E um povo desinformado e sem uma formação crítica pode ser manipulado e, por medo, permanecer obediente e calado!

RE - A Lei 13.415/2017 prevê que os currículos do ensino médio podem ser organizados não apenas em itinerários formativos, mas também arranjos diferenciados - em módulos, créditos, com "terminalidades específicas", com possibilidade de "certificações intermediárias". O que isso pode significar para os jovens estudantes?

Lisete Arelaro - Se estivéssemos numa situação de normalidade política e legislativa no Brasil, em que direitos sociais estivessem resguardados, eu diria que, pelo número de jovens de até 30 anos que não cursaram ou não concluíram o ensino médio regular, flexibilidades seriam bem-vindas, especialmente para inovar em cursos da EJA. Na a atual conjuntura, essas propostas são temerárias, uma vez que o interesse principal desse grupo é enterrar a proposta do ensino médio como etapa final de uma educação básica no Brasil, como direito de todos (as). E aí, a flexibilidade ilimitada vira descompromisso e leviandade educacional.

RE - Em sua análise do cenário político atual, como você avalia os desdobramentos da reforma do ensino médio, cuja resistência dos estudantes secundaristas resultou nas ocupações das escolas em muitas cidades do País?

Lisete Arelaro - O movimento secundarista deu uma lição a todos nós. Eles desencadearam ações para defender suas escolas e uma nova proposta de formação nessa etapa de ensino. Apesar das imensas perseguições que sofreram (e ainda sofrem) deram seu recado e também nós (re)aprendemos que o movimento estudantil existe e está vivo e vai resistir contra a implantação desse simulacro de ensino médio. A reação está presente. E eles (as) têm atuado, às vezes silenciosamente, às vezes de maneira mais visível, mas
"O movimento secundarista deu uma lição a todos nós. Eles desencadearam ações para defender suas escolas e uma nova proposta de formação nessa etapa de ensino. Apesar das imensas perseguições que sofreram (e ainda sofrem) deram seu recado..." 
"Do lado deles, o próprio governo usando a mídia para fazer propaganda enganosa, o Todos pela Educação,

o Unibanco,

a Fundação Ayrton Senna, o Banco Mundial e a Fundação

Lemann. Pode parecer uma luta desproporcional, mas nós ficaremos."

suas lutas estão mais vivas do que nunca! Enquanto o governo não ouvir essas vozes, nenhuma reforma, de fato, se implantará.

RE - Sabemos que as reformas educacionais se constituem, historicamente, em campos de disputa e não foi diferente com a atual reforma do ensino médio. Quais foram os objetos fundamentais em litígios e que atores sociais compareceram a esta "cena"?

Lisete Arelaro - A disputa pelo ensino médio generalista ser, de fato, a última etapa da educação básica para todos os alunos (as) me parece a mais importante. O oferecimento de "percursos formativos", sem nenhuma explicitação que comprometesse o governo com novas exigências foi a "cereja do bolo" para que a desqualificação do ensino médio e a adoção de uma concepção de formação de mão de obra barata em nível médio não aparecessem como sua verdadeira face. Eu até já ouvi parte do grupo do governo defender que um dos "percursos formativos" que pode traduzir um dos "arranjos curriculares" (Art.4º da Lei) é o retorno generalizado do Curso Normal para a formação de professores dos anos iniciais e da educação infantil, agora sem "aquele exagero de formação teórica", e que prepare as estudantes para seguir, de forma obediente, os conteúdos propostos na BNCC. Em relação aos atores sociais, pude acompanhar a movimentação, de nosso lado, de estudantes (UNE e movimentos estudantis independentes), sindicatos de professores, em especial a CNTE, e das associações científicas como a Anped, a Anfope, a Anped, a Anpae, o Forumdir, a ABDC e a Fineduca, com elaboração de documentos, assinaturas conjuntas e participação em muitos debates, conversas, audiências públicas e seminários/congressos/encontros. Do lado deles, o próprio governo usando a mídia para fazer propaganda enganosa, o Todos pela Educação, o Unibanco, a Fundação Ayrton Senna, o Banco Mundial e a Fundação Lemann. Pode parecer uma luta desproporcional, mas nós ficaremos, porque lutamos por uma sociedade solidária e menos desigual; e eles, por vantagens econômicas, e por isso passarão...

Recebido em 20/06/2017 e aprovado em 23/06/2017

\section{Notas}

1 Professora titular sênior do Departamento de Administração Escolar e Economia da Educação da Faculdade de Educação da Universidade de São Paulo (USP) e sua ex-diretora, presidente da Associação Nacional de Pesquisa em Financiamento da Educação (Fineduca) e pesquisadora na área de Política Educacional, Planejamento e Avaliação Educacional, Financiamento da Educação Básica e Educação Popular. 